\title{
POPULASI FITOPLANKTON SKELETONEMA DI ESTUARIA BANYUASIN, SUMATERA SELATAN
}

\section{SKELETONEMA POPULATION IN BANYUASIN ESTUARY OF SOUTH SUMATRA}

\author{
Riris Aryawati*, T. Zia Ulqodry, Heron Surbakti, dan Ellis N. Ningsih \\ Program Studi Ilmu Kelautan, Fakultas MIPA, Universitas Sriwijaya \\ *E-mail: ririsaryawati@yahoo.com
}

\begin{abstract}
Phytoplankton in the sea has an important role in the food chain and is responsible for primary production. The abundance and number of phytoplankton types will indirectly affect the fertility level of a water. This study aims to determine the presence of phytoplankton in terms of density and various diversity indices like Shannon-Wiener Diversity Index (H'), Evenness Index (E), and Simpson Dominance Index (D) in estuary Banyuasin, South Sumatra. The study was conducted in September 2017 at eleven stations. Examples of phytoplankton are taken on the surface of the waters by using a cone-shaped plankton net with a diameter of $30 \mathrm{~cm}$, a length of $100 \mathrm{~cm}$ and a mesh size of $30 \mu \mathrm{m}$. The study indicated the availability of 17 phytoplankton genera from the Bacillariophyceae class, and there was high density of the Skeletonema, with a composition of $98.71 \%$. The values of $H^{\prime}, E$ and D showed the existence of unstable phytoplankton community structure condition. The Shannon-Wiener diversity index value in this study ranged from 0.02 to 0.87 , which means a community with low diversity, evennes values ranging from 0.01 to 0.25 , meaning communities with uniform uniformity and high dominance values ranging from 0.67-0.99.
\end{abstract}

Keywords: Banyuasin estuarine, skeletonema, South Sumatra

\begin{abstract}
ABSTRAK
Fitoplankton di laut mempunyai peranan penting sebagai pembentuk dasar dari rantai makanan (foodchain) dan bertanggung jawab dalam produksi primer (primary production). Kelimpahan dan jumlah jenis fitoplankton secara tidak langsung akan mempengaruhi tingkat kesuburan suatu perairan. Penelitian ini bertujuan untuk mengetahui keberadaan fitoplankton ditinjau dari kelimpahan, indeks keragaman, indeks keseragaman, dan indeks dominansi di estuaria Banyuasin, Sumatera Selatan. Penelitian dilakukan pada bulan September 2017 di sebelas stasiun. Contoh fitoplankton diambil di permukaan perairan dengan menggunakan jaring plankton yang berbentuk kerucut dengan diameter 30 $\mathrm{cm}$, panjang $100 \mathrm{~cm}$ dan ukuran mata jaring $30 \mu \mathrm{m}$. Hasil penelitian menemukan 17 marga fitoplankton dari kelas Bacillariophyceae, dan terdapat ledakan populasi dari marga Skeletonema, dengan komposisi sebesar 98,71\%. Nilai indeks keragaman (H'), indeks keseragaman (E) dan indeks dominansi (D) memperlihatkan adanya kondisi struktur komunitas fitoplankton yang tidak stabil. Nilai indeks keragaman pada penelitian ini berkisar antara 0,02-0,87 yang berarti komunitas dengan keanekaragaman yang rendah, nilai keseragaman berkisar antara 0,01-0,25 yang berarti komunitas dengan keseragaman tidak merata dan nilai dominansi berkisar antara 0,67-0,99 yang berarti terjadi dominansi jenis fitoplankton.
\end{abstract}

Kata kunci: estuaria Banyuasin, skeletonema, Sumatera Selatan

\section{PENDAHULUAN}

Perairan pesisir Sumatera Selatan merupakan wilayah perairan yang banyak bermuara sungai besar yang berperan penting dalam roda kehidupan masyarakat Sumatera Selatan. Pada muara ini terjadi akumulasi aliran air dari Sungai Musi, Sungai Banyuasin dan beberapa sungai kecil di Sumatera Selatan. Wilayah ini dari hulu sampai hilir sangat banyak dimanfaatkan masyarakat untuk berbagai kegiatan seperti kegiatan berbagai jenis pabrik (pupuk, karet, minyak), pemukiman, kegiatan penangkapan 
ikan, kegiatan pertambakan, pertanian, perkebunan, jalur transportasi dan berbagai kegiatan lainnya. Kegiatan-kegiatan ini akan meningkatkan beban masukan yang berupa limbah pertanian, limbah domestik dan limbah industri. Hal ini akan mempengaruhi organisme dan biota yang ada di dalam perairan. Salah satunya adalah fitoplankton yang berperan sebagai produsen dalam tingkatan rantai makanan pada perairan tersebut.

Plankton khususnya fitoplankton mempunyai peranan penting dalam rantai makanan di ekosistem akuatik dan sering dijadikan indikator kestabilan, kesuburan dan kualitas perairan. Fitoplankton dapat berperan sebagai salah satu satu parameter ekologi dalam menggambarkan bagaimana kondisi suatu perairan yakni sebagai parameter tingkat kesuburan suatu perairan.

Meningkatnya berbagai aktifitas di perairan pesisir Sumatera Selatan akan mempengaruhi distribusi kelimpahan dan keragaman fitoplankton yang pada akhirnya mempengaruhi kualitas perairan di perairan ini. Menurut Nybakken (1992) dan Nontji (2005) organisme perairan dapat digunakan sebagai indikator kualitas perairan karena habitat, mobilitas dan umurnya yang relatif lama mendiami suatu wilayah perairan. Beberapa penelitian fitoplankton telah beberapa kali dilakukan di wilayah ini
(Aryawati et al., 2005; Aryawati et al., 2016; Aryawati et al., 2017; Isnaini et al., 2011; Surbakti et al., 2011), dan memperlihatkan adanya kecenderungan populasi Skeletonema yang tinggi. Oleh karena itu sangat perlunya kajian mengenai struktur komunitas fitoplankton, khususnya populasi Skeletonema di estuaria Banyuasin. Penelitian ini bertujuan untuk mengetahui keberadaan fitoplankton yang khususnya Skeletonema ditinjau dari kelimpahan, indeks keragaman, indeks keseragaman, dan indeks dominansi fitoplankton di estuaria Banyuasin, Sumatera Selatan.

\section{METODE PENELITIAN}

Penelitian dilakukan di perairan estuaria Banyuasin, Sumatera Selatan di 11 stasiun (Gambar 1). Pengambilan sampel dilakukan pada bulan September 2017. Penentuan lokasi pengambilan sampel dilakukan secara purposive random sampling yaitu metode pengambilan sampel dengan menentukan stasiun secara acak dengan memilih daerah yang mewakili lokasi penelitian. Stasiun penelitian sebanyak 11 stasiun yang meliputi daerah muara sungai yang banyak mendapat pengaruh sungai dan daerah yang banyak mendapat pengaruh dari laut sehingga diharapkan seluruh lokasi penelitian dapat terwakili.

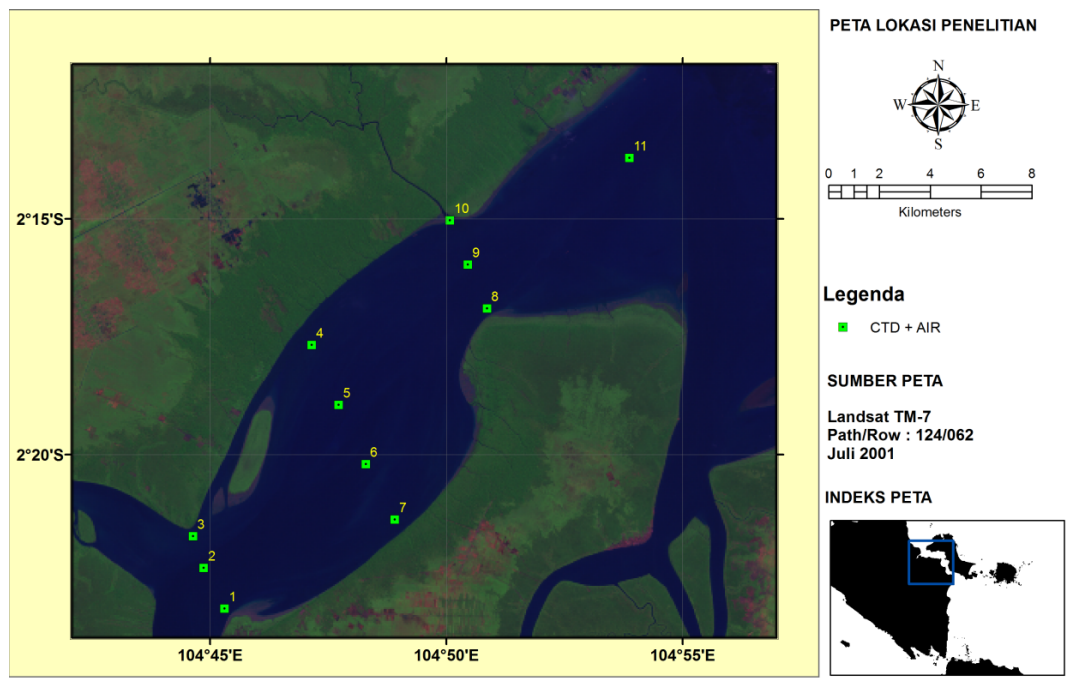

Gambar 1. Peta lokasi penelitian di perairan estuaria Banyuasin Sumatera Selatan. 


\subsection{Pengambilan Sampel Air}

Sampel air diperoleh dengan menggunakan water sampler (kapasitas 1 L), diambil pada bagian permukaan perairan dan disimpan dalam botol polietilen dan selanjutnya disimpan dalam coolbox. Proses selanjutnya dibawa ke laboratorium untuk dianalisis kandungan nitrat dan fosfatnya. Analisis nitrat dilakukan dengan menggunakan metode Moris dan Riley (1963) yang dimodifikasi oleh Grasshoff (Parson et al, 1984), sedangkan analisis fosfat dilakukan menurut metode Murphy dan Riley (1962) dalam Parson et al. (1984).

\subsection{Pengambilan Sampel Fitoplankton}

Pengambilan sampel fitoplankton dengan menggunakan jaring plankton dengan ukuran mata jaring $30 \mu \mathrm{m}$, diameter mulut jaring $30 \mathrm{~cm}$ dan panjang jaring $100 \mathrm{~cm}$. Sampling dilakukan pada permukaan perairan dengan mengambil sampel air sebanyak 100 liter. Filtrat yang terkumpul di botol penampung dimasukkan ke dalam botol sampel $250 \mathrm{ml}$ dan diberi pengawet formalin $4 \%$ (Edler and Elbrachter, 2010).

\subsection{Analisis Sampel Fitoplankton}

Sampel dicacah dan diidentifikasi di laboratorium menggunakan mikroskop binokuler merk Olympus tipe cx 21 . Jenisjenis fitoplankton diidentifikasi sampai tingkat genus dengan menggunakan bantuan buku identifikasi alga plankton (Newell and Newell, 1977; Yamaji, 1984; Tomas, 1997). Pencacahan fitoplankton dilakukan dengan menggunakan "Sedgwik-Rafter Counting Cell" dan hasilnya dinyatakan dalam sel L-1.

Analisis kelimpahan fitoplankton mengacu pada formulasi yang digunakan APHA (1995) yang telah dimodifikasi:

$$
N=\frac{n}{p} x \frac{l_{S R}}{l_{P}} x \frac{V_{l}}{V_{S R C}} x \frac{1}{V_{T}}
$$

Keterangan: $\mathrm{N}=$ kelimpahan Plankton (sel.L$\left.{ }^{1}\right), \mathrm{n}=$ jumlah plankton yang tercacah (sel), $\mathrm{p}$ $=$ jumlah lapang pandang yang diamati, $1_{\mathrm{SR}}=$ luas total lapang pandang Sedgwick Rafter $\left(1000 \mathrm{~mm}^{2}\right), \mathrm{l}_{\mathrm{p}}=$ luas lapang pandang Sedgwick Rafter yang diamati $\left(\mathrm{mm}^{2}\right), \mathrm{V}_{1}=$ volume air contoh yang tersaring $(\mathrm{mL}), \mathrm{V}_{\mathrm{SRC}}$ $=$ volume sedgwick rafter $(1 \mathrm{~mL})$, dan $\mathrm{V}_{\mathrm{T}}=$ volume air yang disaring (L).

Keanekaragaman jenis fitoplankton diketahui berdasarkan persamaan Shannon dan Wiener (1963) dalam Parsons et al. (1984):

$$
\mathrm{H}^{\prime}=\sum_{\mathrm{i}=1}^{\mathrm{n}} \mathrm{P}_{\mathrm{i}} \log _{2} \mathrm{P}_{\mathrm{i}} ; \mathrm{P}_{\mathrm{i}}=\mathrm{n}_{\mathrm{i}} / \mathrm{N}
$$

Keterangan: $\mathrm{H}^{\prime}=$ Indeks Diversitas, $\mathrm{n}_{\mathrm{i}}=$ Jumlah sel fitoplankton jenis ke-I, $\mathrm{N}=$ Jumlah total sel fitoplankton.

Analisis keseragaman menggunakan indeks Evennes dan analisis dominansi menggunakan indeks Simpson (Odum, 1998). Indeks Evennes:

$$
\mathrm{E}=\frac{\mathrm{H}^{\prime}}{\mathrm{H}_{\text {maks }}} \quad ; \mathrm{E}=\frac{\mathrm{H}^{\prime}}{\log _{2} \mathrm{~S}} \ldots \ldots \ldots \ldots(3)
$$

Keterangan: $\mathrm{E}=$ Indeks Evennes, $\mathrm{H}^{\prime}=$ Indeks Diversitas, $\mathrm{H}_{\text {maks }}=\log _{2} \mathrm{~S}$, dan $\mathrm{S}=$ Jumlah spesies.

Indeks dominansi Simpson:

$$
\mathrm{D}=\sum_{\mathrm{i}=1}^{\mathrm{n}}\left(\mathrm{n}_{\mathrm{i}} / \mathrm{N}\right)^{2}
$$

Keterangan $\mathrm{D}=$ Indeks dominansi Simpson, $\mathrm{n}_{\mathrm{i}}=$ Jumlah sel fitoplankton jenis ke-I, dan N $=$ Jumlah total sel fitoplankton.

Data yang telah diperoleh selanjutnya ditampilkan dalam bentuk yaitu tabel dan grafik.

\section{HASIL DAN PEMBAHASAN}

\subsection{Komposisi dan Kelimpahan Fitoplankton}

Komposisi jenis dapat menggambarkan keragaman atau jumlah jenis dalam suatu 
komunitas. Keragaman jenis ini dapat bertambah bila komunitas menjadi semakin stabil dan sebaliknya semakin berkurang bila lingkungan tidak stabil atau mengalami gangguan. Populasi fitoplankton di perairan Banyuasin pada saat penelitian berjumlah 17 genera yang termasuk dalam kelas Bacillariophyceae (Tabel 1).

Tabel 1 dapat dilihat bahwa fitoplankton yang dijumpai di estuaria Banyuasin terdiri atas 17 genera, dan tidak semua genus dijumpai disetiap stasiun. Genus Coscinodiscus, Skeletonema dan Streptotheca dapat dijumpai di setiap stasiun.

Kelimpahan fitoplankton tertinggi dijumpai pada genus Skeletonema dengan komposisi mencapai 98,71\% dan dijumpai pada semua stasiun (Gambar 2 dan Tabel 1).

Kelimpahan Skeletonema juga terlihat sangat melimpah dibandingkan dengan genus yang lain (Gambar 2). Penelitian sebelumnya (Aryawati et al., 2005; Aryawati et al., 2016; Aryawati et al., 2017; Isnaini et al., 2011; Surbakti et al., 2011) diketahui fitoplankton dari genus Skeletonema ini mendominasi populasi fitoplankton di perairan Banyuasin secara umum. Beberapa perairan di Indonesia genus ini sering ditemukan dalam jumlah besar (Soedibjo, 2006; Thoha, 2013; Thoha dan Aryawati, 2014). Hasil penelitian Soedibjo (2007) di perairan Teluk Jakarta yang menunjukkan tingginya kelimpahan Skeletonema dan Chaetoceros, yang mengindikasikan bahwa kedua jenis ini secara bersamaan memanfaatkan nutrisi dengan laju yang relatif sama. Sutomo (2013) menyatakan bahwa Skeletonema termasuk jenis diatom yang sering blooming pada suatu perairan termasuk di Teluk Sekotong dan Teluk Jakarta. Lebih lanjut dinyatakan bahwa hal ini mungkin dikarenakan Skeletonema lebih mudah menyerap nutrien dan ukuran selnya relatif besar sehingga mampu berkompetisi dengan marga fitoplankton lainnya. Penelitian yang dilakukan Hasani et al. (2012) menunjukkan bahwa adanya korelasi positif yang kuat antara konsentrasi unsur hara $\mathrm{N}$ dan $\mathrm{P}$ dengan potensi kemunculan fitoplankton pada berbagai lokasi budidaya perikanan di Teluk Lampung. Pednekar et al. (2012) menyatakan bahwa kelimpahan spesies fitoplankton berkaitan dengan peningkatan nutrien yang masuk ke perairan pesisir yang berasal dari muara sungai.

Tabel 1. Komposisi fitoplankton pada setiap stasiun.

\begin{tabular}{|c|c|c|c|c|c|c|c|c|c|c|c|c|}
\hline \multirow{2}{*}{ No } & \multirow{2}{*}{ Jenis marga } & \multicolumn{11}{|c|}{ Stasiun } \\
\hline & & 1 & 2 & 3 & 4 & 5 & 6 & 7 & 8 & 9 & 10 & 11 \\
\hline 1 & Bacteriastrum & $\mathrm{v}$ & - & - & $\mathrm{v}$ & - & - & $\mathrm{v}$ & $\mathrm{v}$ & $\mathrm{v}$ & $\mathrm{v}$ & $\mathrm{v}$ \\
\hline 2 & Chaetoceras & $\mathrm{v}$ & $\mathrm{v}$ & $\mathrm{v}$ & $\mathrm{v}$ & $\mathrm{v}$ & $\mathrm{v}$ & $\mathrm{v}$ & $\mathrm{v}$ & $\mathrm{v}$ & $\mathrm{V}$ & $\mathrm{v}$ \\
\hline 3 & Coscinodiscus & $\mathrm{v}$ & $\mathrm{v}$ & $\mathrm{v}$ & $\mathrm{V}$ & $\mathrm{v}$ & $\mathrm{V}$ & $\mathrm{V}$ & $\mathrm{v}$ & $\mathrm{v}$ & $\mathrm{V}$ & $\mathrm{v}$ \\
\hline 4 & Ditylum & - & - & - & $\mathrm{v}$ & $\mathrm{v}$ & $\mathrm{V}$ & $\mathrm{v}$ & $\mathrm{v}$ & $\mathrm{v}$ & $\mathrm{V}$ & $\mathrm{v}$ \\
\hline 5 & Euglena & $\mathrm{v}$ & $\mathrm{v}$ & $\mathrm{v}$ & $\mathrm{v}$ & - & $\mathrm{v}$ & - & - & - & - & $\mathrm{v}$ \\
\hline 6 & Guinardia & $\mathrm{v}$ & $\mathrm{v}$ & $\mathrm{v}$ & - & $\mathrm{v}$ & $\mathrm{v}$ & $\mathrm{V}$ & - & - & $\mathrm{v}$ & - \\
\hline 7 & Hemiaulus & - & - & - & $\mathrm{v}$ & - & $\mathrm{v}$ & $\mathrm{V}$ & $\mathrm{v}$ & $\mathrm{v}$ & $\mathrm{v}$ & $\mathrm{v}$ \\
\hline 8 & Lauderia & - & - & - & $\mathrm{v}$ & - & - & $\mathrm{v}$ & - & $\mathrm{v}$ & - & - \\
\hline 9 & Leptocylindrus & - & - & - & $\mathrm{v}$ & $\mathrm{v}$ & - & - & $\mathrm{v}$ & $\mathrm{v}$ & $\mathrm{V}$ & - \\
\hline 10 & Nitzschia & $\mathrm{V}$ & $\mathrm{v}$ & $\mathrm{V}$ & - & - & $\mathrm{V}$ & $\mathrm{v}$ & - & - & - & $\mathrm{v}$ \\
\hline 11 & Odontellaa & - & - & $\mathrm{V}$ & $\mathrm{V}$ & $\mathrm{v}$ & $\mathrm{V}$ & $\mathrm{V}$ & $\mathrm{V}$ & $\mathrm{v}$ & $\mathrm{V}$ & $\mathrm{v}$ \\
\hline 12 & Planktoniella & - & - & $\mathrm{V}$ & - & - & $\mathrm{V}$ & $\mathrm{v}$ & - & $\mathrm{v}$ & $\mathrm{V}$ & - \\
\hline 13 & Pleurosigma & $\mathrm{V}$ & $\mathrm{v}$ & - & $\mathrm{V}$ & $\mathrm{v}$ & $\mathrm{v}$ & $\mathrm{v}$ & - & $\mathrm{v}$ & $\mathrm{V}$ & $\mathrm{v}$ \\
\hline 14 & Skeletonema & $\mathrm{v}$ & $\mathrm{v}$ & $\mathrm{v}$ & $\mathrm{V}$ & $\mathrm{v}$ & $\mathrm{v}$ & $\mathrm{V}$ & $\mathrm{v}$ & $\mathrm{v}$ & $\mathrm{V}$ & $\mathrm{v}$ \\
\hline
\end{tabular}




\begin{tabular}{|c|c|c|c|c|c|c|c|c|c|c|c|c|}
\hline \multirow{2}{*}{ No } & \multirow{2}{*}{ Jenis marga } & \multicolumn{11}{|c|}{ Stasiun } \\
\hline & & 1 & 2 & 3 & 4 & 5 & 6 & 7 & 8 & 9 & 10 & 11 \\
\hline 15 & Streptotheca & $\mathrm{V}$ & $\mathrm{v}$ & $\mathrm{v}$ & $\mathrm{v}$ & $\mathrm{v}$ & $\mathrm{v}$ & $\mathrm{v}$ & $\mathrm{v}$ & $\mathrm{v}$ & $\mathrm{V}$ & $\mathrm{v}$ \\
\hline 16 & Thalassionema & $\mathrm{V}$ & - & $\mathrm{V}$ & - & $\mathrm{V}$ & $\mathrm{v}$ & $\mathrm{v}$ & $\mathrm{V}$ & - & $\mathrm{v}$ & $\mathrm{V}$ \\
\hline 17 & Thalassiothrix & - & - & $\mathrm{V}$ & $\mathrm{v}$ & $\mathrm{V}$ & $\mathrm{V}$ & $\mathrm{v}$ & $\mathrm{V}$ & $\mathrm{v}$ & $\mathrm{v}$ & $\mathrm{V}$ \\
\hline
\end{tabular}

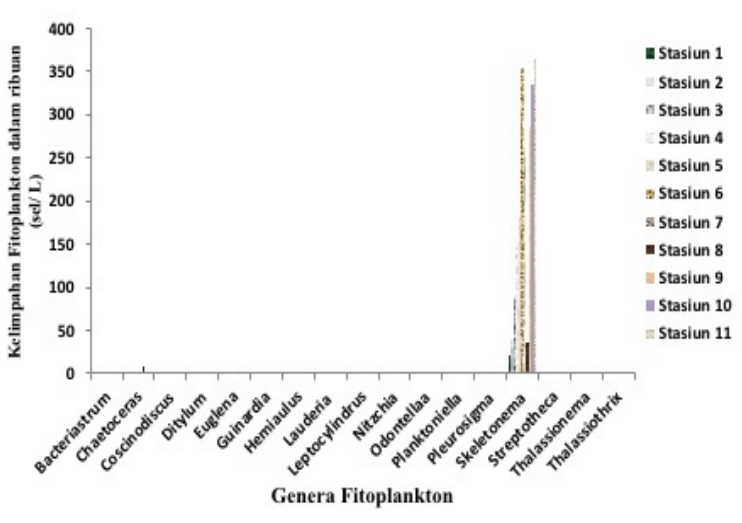

Gambar 2. Kelimpahan fitoplankton pada setiap marga.

Melimpahnya Skeletonema diduga karena tingginya kandungan nitrat dan fosfat, pada penelitian ini ditemukan kandungan nitrat dan fosfat yang tinggi. Konsentrasi nitrat berkisar antara 1,60-3,57 $\mathrm{mgL}^{-1}$ dan konsentrasi fosfat berkisar antara 0,43-1,25 $\mathrm{mgL}^{-1}$. Hal ini sejalan dengan pernyataan Aryawati et al. (2016) dan Aryawati et al. (2017), yang menyatakan bahwa terjadinya peningkatan nutrien khususnya nitrat, fosfat dan silikat dari tahun ke tahun di perairan Banyuasin dapat menimbulkan eutrofikasi dan mengakibatkan terjadinya peningkatan fitoplankton secara cepat, khususnya Skeletonema. Aryawati (2016) menyatakan kelimpahan Skeletonema sangat dipengaruhi oleh konsentrasi nitrat, fosfat dan silikat yang tinggi. Kandungan nutrien di wilayah perairan estuaria Banyuasin terlihat sangat tinggi bila dibandingkan dengan nutrien di Kepulauan Banggai, dengan kandungan nitrat berkisar antara $0,07-0,29 \mathrm{mgL}^{-1}$ dan fosfat berkisar antara $0,005-0,038 \mathrm{mgL}^{-1}$ (Thoha dan Rachman, 2013). Sutomo (2013) menyatakan bahwa adanya dominasi oleh marga Skeletonema dan Chaetoceros di perairan Teluk Kodek dan Teluk Sekotong,
Lombok karena marga tersebut mampu bersaing dalam menyerap hara lebih cepat. Hasil penelitian Widiarti (2000) menunjukkan bahwa Skeletonema berkorelasi positif dengan fosfat di perairan, sedangkan Chaetoceros menyukai salinitas yang rendah. Lagus et al. (2004) menyatakan bahwa diatom (Chaetoceros wighamii dan Skeletonema costatum) mempunyai respon yang sangat cepat terhadap penambahan nutrien dan menjadi kelompok yang dominan.

\subsection{Struktur Komunitas Fitoplankton}

Komunitas fitoplankton di perairan estuaria Banyuasin dapat dilihat dari nilai indeks keanekaragaman ( $\left.\mathrm{H}^{\prime}\right)$, indeks keseragaman (E) dan indeks dominansi (D). Nilai indeks keragaman (H'), indeks keseragaman (E) dan indeks dominansi (D) memperlihatkan adanya kondisi struktur komunitas fitoplankton yang tidak stabil. Nilai indeks keragaman pada penelitian ini berkisar antara 0,02-0,87 yang berarti komunitas dengan keanekaragaman yang rendah, nilai keseragaman berkisar antara 0,01-1,25 yang berarti komunitas dengan keseragaman tidak merata dan nilai dominansi berkisar antara 0,67-0,99 yang berarti terjadi dominansi jenis fitoplankton.

Nilai-nilai Indeks tersebut memberikan petunjuk bahwa kondisi perairan di estuaria Banyuasin dalam keadaan tidak stabil, dengan adanya dominansi yang sangat tinggi dari marga Skeletonema.

\section{KESIMPULAN}

Kelimpahan fitoplankton tertinggi dijumpai pada genus Skeletonema yang mencapai $98,71 \%$ dari total kelimpahan 
fitoplankton yang ditemukan. Kondisi demikian mengindikasikan telah terjadi ledakan populasi Skeletonema di wilayah perairan estuaria Banyuasin Sumatera Selatan.

\section{UCAPAN TERIMA KASIH}

Ucapan terima kasih disampaikan kepada Kemenristek-Dikti dan Universitas Sriwijaya yang telah mendanai penelitian ini melalui Anggaran SP. DIPA Universitas Sriwijaya Nomor 042.01.2.400953/2017 dan sesuai dengan Surat Perjanjian Penugasan Pelaksanaan Penelitian Unggulan Kompetitif Universitas Sriwijaya Nomor 1012/UN9.3. 1/PP/2017.

\section{DAFTAR PUSTAKA}

American Publich Health Association (APHA). 1995. American Water Works Association dan Water Pollution Control Federation Standard methods for the examination of water and wastewater. $19^{\text {th }}$ ed. APHA New York. 1015 p.

Aryawati, R. 2016. Eksplorasi harmful algal blooms (habs) dan hubungannya dengan karakteristik lingkungan di perairan pesisir Sumatera Selatan. Disertasi. Program Studi Ilmu Kelautan. IPB. Bogor. $111 \mathrm{hlm}$.

Aryawati, R., D.G. Bengen, T. Prartono, and H. Zulkifli. 2016. Harmful algal in Banyuasin Coastal Waters, South Sumatera. Biosaintifika, 8(2):231239.

Aryawati, R., D.G. Bengen, T. Prartono, and H. Zulkifli. 2017. Abundance of phytoplankton in the coastal waters of South Sumatera. Ilmu Kelautan, 22(1):31-39.

Aryawati, R., H. Surbakti, dan T.Z. Ulqodry. 2005. Hubungan kondisi oseanografi dengan kelimpahan fitoplankton di perairan Banyuasin. Prosiding seminar nasional tahunan hasil penelitian perikanan dan kelautan tahun 2005, BRPPU, Palembang. 2729 Juli 2005.

Edler, L. and M. Elbrachter. 2010. The utermohl method for quantitative phytoplankton analysis. In : Karlson et al., (eds.). Microscopic and molecular methods for quantitative phytoplankton analysis. Intergovernmental Oceanograpic Commission, United Nations Educational, Scientific and Cultural Organization. Spain. 13-15 pp.

Hasani, Q., E.M. Adiwilaga, and N.T.M. Pratiwi. 2012. The relationship between the harmful algal blooms (habs) phenomenon with nutrients at shrimp farms and fish cage culture sites in Pesawaran District Lampung Bay. Makara J. of Science, 16(3): 183-191.

Isnaini. 2011. Fitoplankton di perairan Muara Sungai Banyuasin Sumatera Selatan. Makalah disampaikan pada Seminar dan Rapat Tahunan (SEMIRATA) BKS Barat bidang MIPA, Unlam. Banjarmasin. $10 \mathrm{hlm}$.

Lagus, A., J. Suomela, G. Weithoff, K. Heikkilä, H. Helminen, and J. Sipura. 2004. Species-specific differences in phytoplankton responses to $\mathrm{N}$ and $\mathrm{P}$ enrichments and the $\mathrm{N}$ : $\mathrm{P}$ ratio in the Archipelago Sea, northern Baltic Sea. J. of Plankton Research, 26(7): 779798.

Newell, G.E. and R.C. Newell. 1977. Marine plankton; a practical guide. Hutchinson \& Co Ltd. London. 207 p.

Nontji, A. 2005. Laut nusantara. Penerbit Djambatan. Jakarta. $372 \mathrm{hlm}$.

Nybakken, J.W. 1992. Biologi laut; suatu pendekatan ekologis. PT. Gramedia Pustaka Utama. Jakarta. $495 \mathrm{hlm}$.

Odum, E.P. 1998. Dasar-dasar ekologi. Gajah Mada University Press. Yogyakarta. $824 \mathrm{hlm}$.

Parsons, T.R., M. Takashi, and B. Hargrave. 1984. Biological Oceanography 
Process. $3^{\text {rd }}$ ed. Pergamon Press. New York. 330 p.

Pednekar S.M, S.G.P. Matondkar, and V. Kerkar. 2012. Spatiotemporal distribution of harmful algal flora in the tropical estuarine complex of Goa, India. The Scientific World J., 1-11. doi: 10.1100/2012/596276.

Soedibjo, B.S. 2006. Struktur komunitas fitoplankton dan hubungannya dengan beberapa parameter lingkungan di perairan Teluk Jakarta. Oseanologi dan Limnologi di Indonesia, 40:65-78.

Soedibjo, B.S. 2007. Fenomena kehadiran Skeletonema sp di Teluk Jakarta. Ilmu Kelautan, 12(3):119-124.

Surbakti, H., R. Aryawati, dan Isnaini. 2011. Pemodelan sebaran nutrien dan produktivitas primer untuk identifikasi daerah penangkapan ikan di perairan Selat Bangka. Laporan penelitian. Universitas Sriwijaya. Palembang. $858 \mathrm{hlm}$.

Sutomo. 2013. Struktur komunitas fitoplankton di perairan Teluk Sekotong dan Teluk Kodek, Kabupaten Lombok. J. Ilmu dan Teknologi Kelautan Tropis, 5(1):131-144. http://dx.doi.org/10.29244/jitkt.v5i1.7 759.
Thoha, H. 2003. Pengaruh musim terhadap plankton di perairan Riau kepulauan dan Sekitarnya. Makara Sains, 7(2):59-70.

Thoha, H. dan A. Rachman. 2013. Kelimpahan dan distribusi spasial komunitas plankton di perairan Kepulauan Banggai. J. Ilmu dan Teknologi Kelautan Tropis, 5(1):145161.http://dx.doi.org/10.29244/jitkt.v 5i1.7761.

Thoha, H. dan R. Aryawati. 2014. Kondisi fitoplankton di perairan Teluk Jakarta. Seminar Nasional MIPA: Peran MIPA dalam pengelolaan sumberdaya alam untuk kemakmuran bangsa. 516-526 hlm.

Tomas, C.R. 1997. Identifying marine fitoplankton. Academic Press. California. USA. 65 p.

Widiarti, R. 2000. Pola suksesi organisme penyebab red tide Pyrodinium bahamense Plate di Teluk Hurun Lampung Selatan. Institut Pertanian Bogor. Bogor. 80hlm.

Yamaji. 1966. Illustration of the Marine Plankton of Japan. Hoikusho. Osaka, Japan. 369 p.
Diterima : 27 Desember 2017
Direview : 07 Februari 2018
Disetujui : 23 Juli 2018 
